\title{
Применения базальтовой фибры в портландцементных системах
}

\author{
Natalia Levchuck ${ }^{1 *}$, Ekaterina Shlyahova ${ }^{2}$ \\ ${ }^{1}$ Department of Environmental Engineering and Chemistry, Brest State Technical University, \\ Brest, Moskovskaya 267, Belarus \\ ${ }^{2}$ Department of Technology of Construction Production, Brest State Technical University, Brest city, Moskovskaya 267, Belarus \\ * patent@bstu.by
}

\section{Аннотация}

При изучении литературных источников авторами статьи был выявлен ряд спорных вопросов, касающихся физико-химических процессов, протекающих в портландцементной системе с добавлением базальтовой фибры.

В связи с этим была проведена серия экспериментов по изучению свойств базальтовой фибры, обработанной коллоидным гидроксидом алюминия, а также предложена технология введения ее в бетонную смесь и представлен анализ результатов эксперимента.

\section{Ключевые слова}

напрягающий цемент, базальтовая фибра, коллоидный раствор, физико-химические процессы, хемосорбция, портландцементная система

\section{1. Введение}

Исследование отечественными и зарубежными учеными свойств базальтового волокна, как армирующей добавки, показывает высокую эффективность его использования в цементных системах. Вследствие разнообразных составов цементных систем, а также процентного содержания оксиАных составцяющих базальтовых пород, установмено, что цементные системы оказывают различное вмияние на механические и химические свойства базальтового волокна.

В китературных источниках в ияние уАельной поверхности базальтовых волокон на их стойкость в среАе тверАеющего бетона недостаточно изучено и имеется много противоречивых данных. Установлено, что супертонкое волокно реагирует с цементной средой как активная минеральная Аобавка, с последующим образованием кристалмов игомьчатой структуры, в результате чего возрастает прочность бетона. ОАнако, сильнощелочной характер среды оказывает влияние на прочность волокна и, в конечном итоге, на прочностные характеристики армируемого бетона. По вопросу механизма разрушения минеральных волокон в матрицах на основе портландцемента существуют разАичные точки зрения. ОАни авторы (Войлоко 2009) указывают на химическое взаимодействие минерацьного волокна с гиАроксиАом кальция, который 
является основным химическим реагентом, разрушающим его, а симьно развитая поверхность волокна способствует ускорению протекающих процессов разрушения. Аругие (Рабинович 2004) исслеАователи считают, что причиной разрушения минеральных волокон в цементных системах является не только химическое, но и механическое действие процессов, развивающихся в цементном камне, в результате на волокнах возникают трещины, снижающие прочность композиционного материала. Установмено, что на площаАках контакта «волокно-матрица» поА Аействием Аеформации возникают усимия, которые способствуют образованию микротрещин, приводящих в Аальнейшем к снижению работоспособности воцокна, т.е. на границе волокна с матрицей возникает слой новообразований в виде наростов цементной корки, которая приводит в большинстве случаев к уменьшению прочности волокон и, соответственно, к снижению прочности композита.

В результате физико-химических процессов изменяется состав волокон, структура их поверхностного слоя, увеАичиваются размеры имеющихся поверхностных Аефектов - эти процессы, явАяются причиной снижения прочности волокон и композиций на их основе. Вместе с тем, реакции на поверхности «воцокно-цементная матрица» могут и улучшать свойства композита в слеАствие повышения аАгезии матрицы к волокну, монолитности системы и укучшения усмовий совместимости нагружения волокон в композите.

Амя оценки влияния базальтового вомокна на структуру цементной матрицы были сАеланы слеАующие преАположения: - базальтовая фибра, состоящая из аморфной фазы должна активно хемосорбционно взаимодействовать с цементной системой, с образованием низкоосновных гиАросиликатов кальция.

Исследования по изучению взаимоАействия высокоразвитой поверхности волокон Аюбого виАа со щелочными растворами $\mathrm{NaOH}, \mathrm{KOH}, \mathrm{Ca}(\mathrm{OH})_{2}$ обусловмены сложным комплексом процессов, иАущих парахлемьно и накмадывающихся Аруг на Аруга: гиАратация и гиАролиз поверхности волокон; растворение кремнезема, катализируемое ионами $\mathrm{OH}^{-}$; сорбция и хемосорбция, в результате чего ионы камьция и амюминия аАсорбируются на поверхности и связывают кремнезем в труанорастворимые гиАросимикаты и гидроамюминаты камьция, которые созАают на поверхности волокна плотный слой новообразований. Исследованиями (ФеАоркин, Когай 2014) по анализу параметров Алительной прочности волокон базальтового волокна Аиаметром 6,7; 15,1; 33,4; 117,о мкм, поАвергнутых воздействию среАы $\mathrm{Ca}(\mathrm{OH})_{2}$, имитирующих щелочную среАу портланАцементов установлено, что наиболее интенсивное поглощение $\mathrm{CaO}$ из щелочного раствора происходит в первые 3-6 месяцев и степень погмощения возрастает по мере увеличения площаАи поверхности контакта со щелочной среАой. Авторами установлено, что с увеличением диаметра волокна уровень поглощения $\mathrm{CaO}$ еАеницей площади поверхности повышается и имеет затухающий характер. Этот вывоА яв яется сомнительным и опровергает преАЫАущий, поскольку погАотительная или аАсорбционная способность мюбого пористого материала возрастает с увеличением уАельной площаАи поверхности материала.

Очевидно, что, при покучении фибробетонов, с использованием базальтовых волокон, необходимо учитывать размер и Аиаметр волокон. С применением базальтовых волокон диаметром 10-15 мкм, прочность при растяжении образцов увеАичивается Ао 1850-2150 МПа., в то время как в грубодисперсной структуре, с Аиаметром волокна 100 мкм, прочность составцяет 460-220 МПа. Рядом авторов показано, что композиты на основе цементных матриц и базальтовых волокон имеют переменную во времени прочность 
при растяжении вАоль волокон, изменение которой зависит от количества волокон и их диаметра. Минеральные волокна сравнительно больших диаметров от 100 мкм, несмотря на более низкую прочность при разрыве, имеют повышенные значения модукя упругости, но такие вомокна обладают более высоким уровнем коррозионной устойчивости к возАействию среАы гиАратирующего цемента. Исследования показывают, что с увеличением объемного содержания волокон от 1 Ао $3 \%$ и уменьшении Аиаметра от 250 Ао 50 мкм при Алине 40 мм прочностные характеристики повышаются на 26-62\% по сравнению с не армированным бетоном. Из источника (Новицкий, Ефремов 2010) известно, что при содержании волокна в цементной матрице менее $5 \%$ наблюАается тенденция к снижению прочности, в тоже время образцы, содержащие 7-10\% волокон имеют незначительную прочность. Снижение прочности с увекичением процента армирования, авторы объясняют необходимостью увеличения водоцементного отношения, неравномерным распределением волокон по объему смеси, неАоупмотнением смесей неотработанной технологией перемешивания. По мнению авторов (Перфимов, Зубова 2015), исследование влияния высокодисперсных волокнистых наполнителей на механические свойства фибробетонов с использованием базальтового микроармирующего волокна Алиной 12 мм и Аиаметром 10 мкм, привоАит к росту показателей прочности образцов на сжатие и изгиб что объясняется сцеплением базальтовых волокон с цементно- песчаной матрицей. ОАнако, увеличение расхода фибры приводит к ее комкованию, снижению прочностных показателей. По Аанным результатов испытаний оптимацьным яв яется состав фибробетона с концентрацией базальтовой фибры 1,4 кг/м³. ОтсюАа можно сАелать вывоА, что оптимальная концентрация фибры может определяться и оставаться постоянной, но степень Аисперсности волокон фибры может варьироваться, в зависимости от прочностных показателей.

С этой точки зрения особое значение УАемяется технологии приготов ения фибробетонов. Известно, что неравномерное распреАеление волокон по всему объему цементной матрицы явмяется оАной из основных проблем в технологии приготовлении фибробетонов, поскомьку на стадии перемешивания происходит армирование бетонов волокнами. Было преАложено снизить возможность комкования волокна за счет постепенной загрузки волокна в смеситель использование смесей с высокой поАвижностью с применением пластификаторов, снижающих повышенную водопотребность (Зубова 2014).

Таким образом, анализируя данные $и$ тературных источников, можно сделать следующие выводы:

- очевидно, что применение базальтового волокна в качестве армирующего материала явмяется высокоэффективным с точки зрения прочностных и экономических соображений;

- имеются противоречивые данные о механизме химического и хемосорбционного взаимодействия базальтового волокна и цементной системы, поскольку не учитывается возможность участия в химическом взаимоАействии Аругих композиционных составляющих, таких как сульфат-ионы, которые являются обязательным компонентом в составе портландцемента;

- учитывая наличие в составе базальтовой фибры низкоосновных оксиАов, не искиючено их участие как в хемосорбционных процессах, так и в процессах формирования новообразований;

- недостаточно изучены аАсорбционные свойства базальтового волокна, которые зависят от структуры пор, их величины, распреАеления по размерам, необходимо учесть то, что 
аАсорбционная способность материала зависит от микропоровой структуры волокна.

- недостаточно изучено влияние соотношения Аиаметров волокон базальтовой фибры и их объемного содержания в армируемых материалах.

- необходима дальнейшая разработка технологий покучения фибробетонов Аця Аостижения более равномерного распределения армирующих волокон.

\section{2. Методы испытаний}

Учитывая указанные проблемы, в Брестском госуаарственном техническом университете на кафеАре технологии бетона и строительных материалов была преАпринята попытка получения бетонов, армируемых базацьтовой фиброй, преАварительно обработанной колцоидным гиАроксиАом алюминия, полученным электрохимическим способом.

Наши преАположения основываются на том, что фибра, обработанная таким раствором, будет поглощать поверхностью агрегаты комлоиАного $\mathrm{Al}(\mathrm{OH})_{3}$ образуя «защитный» слой, способный реагировать с минералами портландцементного кминкера по механизму гилратации алюминатов кацьция без образования $\mathrm{Ca}(\mathrm{OH})_{2}$ :

$3 \mathrm{CaO} \times \mathrm{AI}_{2} \mathrm{O}_{3}+6 \mathrm{H}_{2} \mathrm{O} \rightarrow$

$\rightarrow 3 \mathrm{CaO} \times \mathrm{AI}_{2} \mathrm{O}_{3} \times 6 \mathrm{H}_{2} \mathrm{O}+867$ Аж/г

Повышение содержания $3 \mathrm{CaO} \times \mathrm{AI}_{2} \mathrm{O}_{3}$ без участия гипса вызывает протекание реакции типа:

$$
\begin{gathered}
3 \mathrm{CaO} \times \mathrm{AI}_{2} \mathrm{O}_{3}+\mathrm{Ca}(\mathrm{OH})_{2}+18 \mathrm{H}_{2} \mathrm{O} \rightarrow \\
\rightarrow 4 \mathrm{CaO} \times \mathrm{AI}_{2} \mathrm{O}_{3} \times 19 \mathrm{H}_{2} \mathrm{O}
\end{gathered}
$$

В результате этой реакции образуются гели гиАроалюминатов кальция, способные заполнить поровые пространства фибры.

Кроме того, в качестве раствора затворения бым использован коциоидный гиАроксиА ахюминия, способный взаимоАействовать с гипсом, соАержащимся в составе портманцемента.
При взаимодействии с гипсом трехкальциевый амюминат образует эттрингит по реакции:

$$
\begin{gathered}
3 \mathrm{CaO} \times \mathrm{AI}_{2} \mathrm{O}_{3} \times 6 \mathrm{H}_{2} \mathrm{O}+3\left(\mathrm{CaSO}_{4} \times\right. \\
\left.\quad \times 2 \mathrm{H}_{2} \mathrm{O}\right) \times(19-2 \mathrm{O}) \mathrm{H}_{2} \mathrm{O} \rightarrow \\
\rightarrow{ }_{3} \mathrm{CaO} \times \mathrm{AI}_{2} \mathrm{O}_{3} \times{ }_{3} \mathrm{CaSO}_{4} \times(31-32) \mathrm{H}_{2} \mathrm{O} .
\end{gathered}
$$

По нашему мнению, он способен оказать влияние на тонкодисперсное вомокно базальтовой фибры, создавая Аополнительные напряжения в поровом пространстве микрофибры, тем самым разрушая ее.

ПосколькУ комАоИАНЫЙ гиАРоксиА аАюминия нахоАится в высокоактивной форме и является раствором затворения появцяется вопрос о способе введения минерального вяжущего вещества. Предварительно обработанная фибра равномерно распределена во всем объеме раствора и при равномерной подаче портиандцемента в раствор, происходит его распределение, а также более интенсивное растворение зерен портландцемента в пространстве между волокнами фибры, что препятствует ее комкованию и в конечном итоге способствует увекичению прочности бетона.

Основным контролируемым параметром напрягающего цемента яв ялась величина самонапряжения (Цемент напрягаюший 2о02). Аля опреАеления основных показателей напрягающего цемента существуют методы и оборудование подробно описанные в СТБ 1335 (Цемент напрягающий 2о02). Аля опреАеления прочности на растяжение при изгибе и прочности на сжатие использоваци гиАравмический пресс марки с CONTROLS AUTOMAX, Аанный пресс явцяется универсацьным мабораторным прессом, позволяющим проводить испытания в условиях контроля скорости сжатия и изгиба, а также нагрузки на образец.

Контрольные измерения связанных Аеформаций опытных образцов произвоАили Аля напрягающего цемента в возрасте $1,3,7,14,21,28$ суток в соответствии с указаниями нормативных Аокументов. 

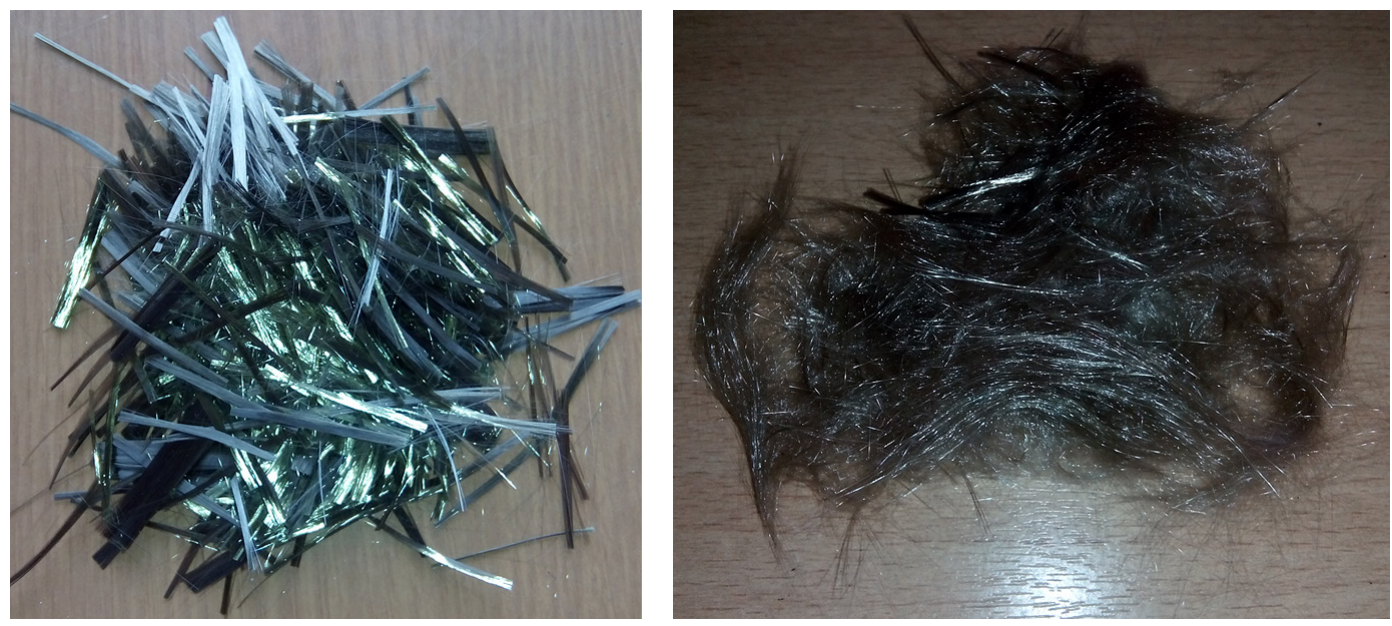

Рисунок 1 - Базальтовая фибра

Таблица 1 - Значения величины самонапряжения напрягающего цемента

Серия образцов Самонапряжение, МПа

(в возрасте 28 суток)

\begin{tabular}{ll}
\hline Серия I & 5,2 \\
Серия II & 6 \\
Серия III & 6,1 \\
Серия IV & 5,5 \\
\hline
\end{tabular}

Испытаниям подвергали слеАующие образцы:

- Серия I - образцы из цементной смеси;

- Серия II - образцы из цементной смеси, армированные базальтовой фиброй;

- $\quad$ Серия III - образцы из цементной смеси, армированные базальтовой фиброй, затворенной комлоидным раствором гиАроксиАа ацюминия;

- Серия IV - образцы из цементной смеси, армированные базальтовой фиброй, измемьченной в мемьнице и затворенной комлоиАным раствором гиАроксиАа алюминия.

Амя нагляАного преАставления протекания процесса роста величины самонапряжения опытных образцов четырех серий на протяжении 28 суток, были построены графические зависимости, преАставленные на рисунке 2.
Конечные значения величины самонапряжения серий образцов из напрягающего цемента в возрасте 28 суток представлены в таблице 1 .

На основании полученных данных бым провеАен сравнительный анализ образцов всех серий. Значения величины самонапряжения образцов армированных базальтовой фиброй (серия II, III, IV) превышают значения образцов, не армированных базальтовой фиброй (серия I).

Определение прочности на сжатие и растяжение при изгибе цементных растворов серий I, II, III, IV выполняли в возрасте 3,7,14 и 28 суток. 


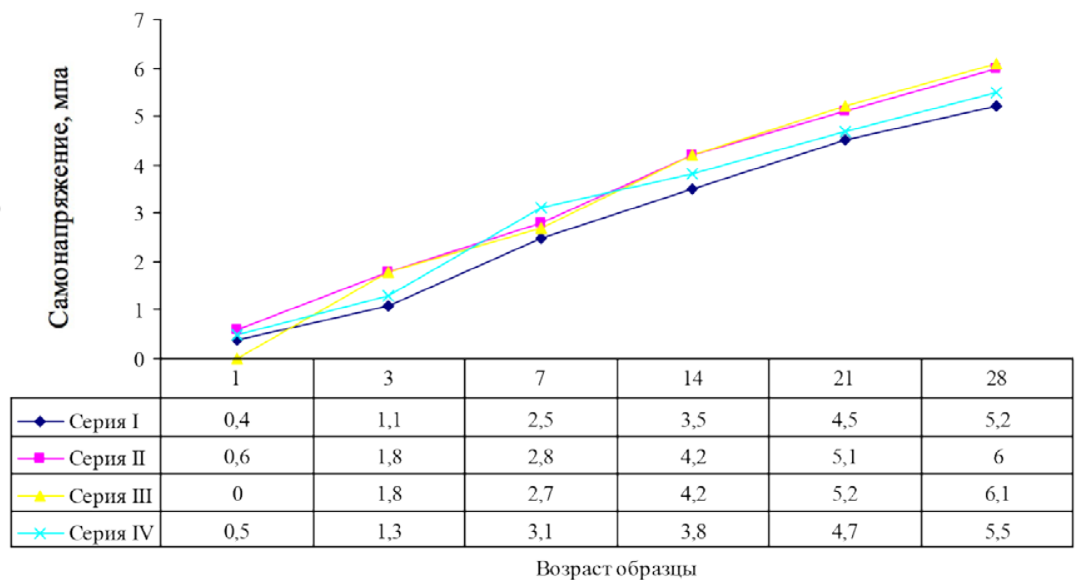

Рисунок 2 - График развития самонапряжения во времени

\section{3. Результаты}

Результаты испытаний представлены в виде гистограмм на рисунках 3,4. 3начения прочности на сжатие и на растяжение при изгибе образцов из напрягающего цемента в возрасте 28 суток преАставлены в таблице 2.

Таблица 2 -Прочностные характеристики напрягающего цемента

\begin{tabular}{lcc}
\hline \multicolumn{1}{c}{ Серия образцов } & $\begin{array}{c}\text { Средняя прочность на растяжение } \\
\text { при изгибе, МПа (в возрасте 28 суток) }\end{array}$ & $\begin{array}{c}\text { Средняя прочность на сжатие, МПа } \\
\text { (в возрасте 28 суток) }\end{array}$ \\
\hline Серия I & 8,06 & 57,3 \\
Серия II & 10,42 & 60,62 \\
Серия III & 8,79 & 60,48 \\
Серия IV & 7,82 & 64,04 \\
\hline
\end{tabular}

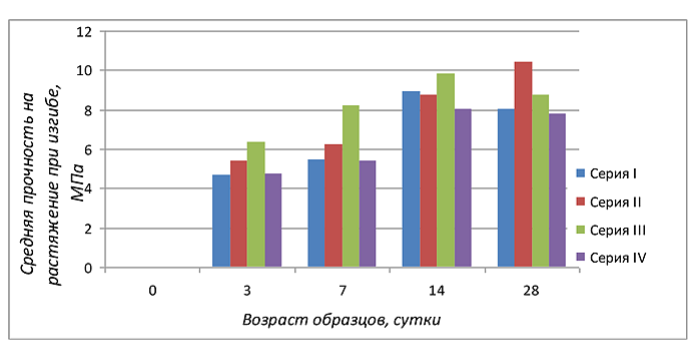

Рисунок 3 - Прочностные характеристики опытных образцов на растяжение при изгибе

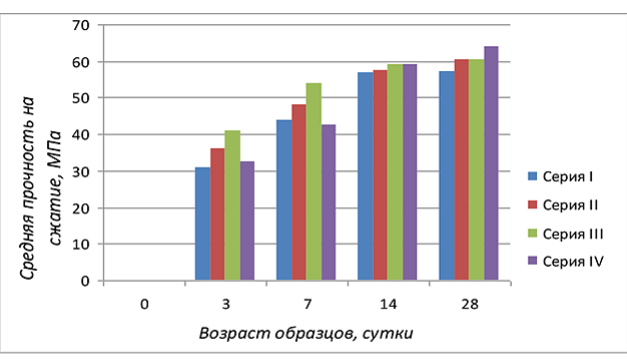

Рисунок 4 - Прочностные характеристики опытных образцов на сжатие 


\section{4. Выводы}

Прочность на растяжение при изгибе у образцов с базальтовой фиброй, обработанной комлоиАным раствором гиАроксида алюминия равномерно возрастает и показывают самые высокие результаты на протяжении 28 суток тверАения.

Прочность на растяжение при изгибе образцов с измельченной фиброй имеет несколько меньшие значения, однако, в периоА тверАения с 7 по 14 сутки резко увекичивается набор прочности на изгиб на 19\%, в то время как прочность образцов с базальтовой фиброй возрастает только на $11 \%$.

В то же время самую высокую прочность на сжатие показывают образцы с измельченной базальтовой фиброй. Такой результат подтверждает участие измельченной базальтовой фибры в процессах структурообразования цементного камня и подтвержАает ее модифицирующие свойства. ОАнако, измемьчение фибры снижает ее армирующие показатели.

Участие комлоидного раствора. ИсслеАование показали, что при обработке базальтовой фибры раствором комлоиАного гиАроксиАа аАюминия прочностные показатели образцов за 28 суток тверАения возрастают на $33 \%$ относительно контрольной серии образцов. Увекичение прочности образцов на изгиб можно объяснить оАновременным вАиянием

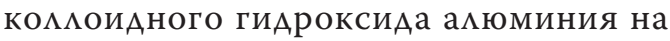
хемосорбционные процессы базацьтового волокна и на ускорение процессов растворения и химического взаимодействия минералов портландцементного кАинкера с КОАлОИАНЫМ ГИАРОКСИАОМ аАюМИнИЯ. Кроме того, гиАроксиА кацьция, явАяющийся основным химическим реагентом разрушающим базальтовое волокно буАет участвовать в процессах образования алюмосицикатов по механизму:

$$
\begin{gathered}
3 \mathrm{CaO} \times \mathrm{AI}_{2} \mathrm{O}_{3}+\mathrm{Ca}(\mathrm{OH})_{2}+18 \mathrm{H}_{2} \mathrm{O} \rightarrow \\
\rightarrow 4 \mathrm{CaO} \times \mathrm{AI}_{2} \mathrm{O}_{3} \times 19 \mathrm{H}_{2} \mathrm{O}
\end{gathered}
$$

А участие метакаолина и гипса в процессах структурообразования цементного камня может происходить не на поверхности базальтового волокна, а на поверхности агрегатов комиоиАного гиАроксиАа алюминия аАсорбированного базальтовой фиброй

$$
\begin{gathered}
3 \mathrm{CaO} \times \mathrm{AI}_{2} \mathrm{O}_{3} \times 6 \mathrm{H}_{2} \mathrm{O}+3\left(\mathrm{CaSO}_{4} \times\right. \\
\left.\quad \times 2 \mathrm{H}_{2} \mathrm{O}\right) \times(19-2 \mathrm{O}) \mathrm{H}_{2} \mathrm{O} \rightarrow \\
\rightarrow{ }_{3} \mathrm{CaO} \times \mathrm{AI}_{2} \mathrm{O}_{3} \times{ }_{3} \mathrm{CaSO}_{4} \times(31-32) \mathrm{H}_{2} \mathrm{O} .
\end{gathered}
$$

По нашему мнению такие процессы приводят к формированию более прочной структуры цементного камня и бетона в целом.

\section{Литература}

Воймоков И.А., Канаев С.Ф., 2009, Базальтофибробетон. Исторический экскурс, Инженерно-строительный журнал, no. 4. 26-31. (Voylokov I.A., Kanayev S.F., 2009, Bazal'tofibrobeton. Istoricheskiy.ekskurs, Inzhenerno-stroitel'nyy zhurnal, no. 4. 26-31.)

Рабинович Ф.Н., 2004, Композиты на основе дисперсно-армированных бетонов. Вопросы теории и проектирования, технология, конструкции, Москва: М.: АВC. (Rabinovich F.N., 2004, Kompozity na osnove dispersno-armirovannykh betonov. Voprosy teorii i proyektirovaniya, tekhnologiya, konstruktsii, Moskva: M.: ABC.)

ФеАоркин С., Когай Э., 2014, Стойкость базальтово говолокна в карбонатных дисперсно-армированных бетонах, MOTROL Commission of Motorization and Energetics in Agriculture, vol. 16, no. 1, 25-30. (Fedorkin S., Kogay.E., 2014, Stoykost' bazal'tovo govolokna v karbonatnykh dispersno-armirovannykh betonakh, MOTROL Commission of Motorization and Energetics in Agriculture, vol. 16, no. 1, 25-30.)

Новицкий А.Г., Ефремов М.В., 2010, Аспекты применения базальтовой фибры для армирования бетонов, Сборник Строительные материалы, изделия и санитарная техника, no. 36. (Novitskiy A.G., Yefremov M.V., 2010, Aspekty primeneniya bazal'tovoy fibry dlya armirovaniya betonov, Sbornik Stroitel'nyye materialy, izdeliya i sanitarnaya tekhnika, no. 36.)

Перфимов В.А., Зубова М.О., 2015, Влияние базальтовых волокон на прочность мелкозернистых фибробетонов, Интернет-Вестник ВолгГУСУ. Сер.: Политематическая, Вып. 1(37), http//www.vestnik/vgasu.ru. (Perfilov V.A., Zubova M.O., 2015, Vliyaniye bazal'tovykh volokon 
na prochnost' melkozernistykh fibrobetonov, Internet-Vestnik VolgGUSU. Ser.: Politematicheskaya, Vyp. 1(37) http//www.vestnik/vgasu.ru.)

Зубова М.О, 2014, Мелкозернистые бетоны с применением базальтовой ббибры и комплексных модифииирующих добавок, ВолгограА. (Zubova M.O, 2014, Melkozernistyye betony sprimeneniyem bazal'tovoy fibry i kompleksnykh modifitsiruyushchikh dobavok, Volgograd.)
Цемент напрягаюший. Технические условия: СТБ 1335-2002, - ВвеА. 01.01.2003 - Мн.; Минстройархитектуры, 2002. - 11 с. (Tsement napryagayushchiy. Tekhnicheskiye usloviya: STB 1335-2002, - Vved. 01.01.2003 - Mn.; Minstroyarkhitektury, 2002. $-11 \mathrm{~s}$ )

\title{
Applications of basalt fibre in Portland cement systems
}

\begin{abstract}
While studying the research sources, the authors of the article investigated a number of issues concerning the physicochemical processes taking place in the Portland cement system with the addition of basalt fibre. A series of experiments was conducted to study the properties of basalt fibre treated with colloidal aluminium hydroxide, the technology of injection fibre into the concrete mixture was proposed and an analysis of the results of the experiment was presented.
\end{abstract}

\section{Keywords}

straining cement, basalt fibre, colloidal solution, physicochemical processes, chemisorption, Portland cement system

\section{Zastosowania włókna bazaltowego w cementach portlandzkich}

\section{Streszczenie}

W badaniach źródeł literatury przedmiotu autorzy artykułu ujawnili szereg kontrowersyjnych zagadnień związanych z procesami fizykochemicznymi zachodzącymi w systemie cementu portlandzkiego z dodatkiem włókna bazaltowego. W związku z tym przeprowadzono serię eksperymentów w celu zbadania właściwości włókna bazaltowego potraktowanego koloidalnym wodorotlenkiem glinu. Zaproponowano technologię wprowadzania włókna bazaltowego do mieszanki betonowej i przedstawiono analizę wyników eksperymentalnych.

\section{Stowa kluczowe}

cementowanie, włókno bazaltowe, roztwór koloidalny, procesy fizykochemiczne, chemisorpcja, cement portlandzki 